\title{
Penggunaan Blog dan YouTube sebagai Media e-Learning di Madrasah Mu'allimin Mu'allimat Rembang
}

\author{
A. Aviv Mahmudi \\ STIE YPPI Rembang, Rembang - Indonesia
}

\begin{abstract}
ABSTRAK
E-Learning adalah suatu sistem pendidikan yang memanfaatkan teknologi informasi dalam proses belajar mengajar. Kurangnya pengetahuan tenaga pengajar mengenai teknologi informasi membuat proses belajar mengajar di Madrasah Mu'allimin Mu'allimat Rembang menjadi terhambat karena kurang mampu menyesuaikan dengan perkembangan teknologi dan menjadi salah satu faktor penurunan minat belajar siswa. Dari permasalah tersebut, kami merencanakan program dengan memanfaatkan teknologi informasi digital sebagai media pembelajaran seperti pemanfaatan platform Blog dan YouTube. Program ini bertujuan untuk meningkatkan kemampuan guru dalam penggunaan suatu Blog dan chanel YouTube sebagai media pembelajaran. Metode pelaksanaan yang dilakukan adalah sosialisasi terkait Blog dan YouTube, workshop pembuatan Blog dan YouTube, serta evaluasi dan pendapingan. Program ini menghasilkan luaran berupa Blog dan channel YouTube bagi masingmasing guru di Madrasah Mu'allimin Mu'allimat Remang sehingga siswa dapat mengakses Blog maupun channel YouTube sebagai bahan belajarnya. Dengan adanya Blog dan channel YouTube tersebut, maka pembelajaran semakin optimal sehingga kualitas pendidikan diharapkan terus meningkat.
\end{abstract}

Kata kunci: : e-learning; madrasah mu'allimin muallimat Rembang; Blog; YouTube

\begin{abstract}
E-Learning is an educational system or concept that utilizes information technology in the teaching and learning process. The lack of knowledge of the teaching staff regarding information technology has hampered the teaching and learning process at Madrasah Mu'allimin Mu'allimat Rembang because it is not able to adapt to technological developments and is one of the factors in decreasing student interest in learning, from these problems we plan programs using information technology digital as a learning medium such as the use of the Blog and YouTube platforms. This program aims to improve the ability of teachers to use a Blog and YouTube channel as a learning medium. The method used in this research is the action research method. The steps taken include observation of the research location, socialization about Blog and YouTube, workshop making Blog and YouTube, evaluation and accompaniment. This program produces an output in the form of a Blog and a YouTube channel for each teacher at Madrasah Mu'allimin Mu'allimat Remang and students can access Blog and YouTube channels as learning materials. With this Blog and YouTube channel, learning will be more optimal so that the quality of education increases.
\end{abstract}

Keywords: e-learning; madrasah mu'allimin muallimat Rembang; Blog; YouTube 


\section{PENDAHULUAN}

Pandemi COVID-19 telah mengubah berbagai aspek kehidupan manusia, termasuk dunia Pendidikan dan elemen pendidikan harus beradaptasi (Herliandry, 2020). Pendidikan pada masa pandemi perlu melakukan penguatan model pembelajaran secara dalam jaringan (daring). Melalui pembelajaran daring akan tercipta model pendidikan dengan konsep lingkungan belajar modern (Elisvi dkk, 2020).

Proses pembelajaran yang awalnya dilakukan secara tatap muka di sekolah kini menjadi pembelajaran daring yang dilakukan dari rumah. Pemanfaatan teknologi informasi sangat membantu dalam proses pembelajaran tersebut (Astini, 2020). Era modern yang ditandai dengan pesatnya perkembangan teknologi informasi dan komunikasi telah berpengaruh besar dalam dunia pendidikan. Internet kini telah menjadi sumber belajar alternatif, pembelajaran tanpa dibatasi ruang dan waktu. Pembelajaran sekarang bersifat luwes, tidak menuntut pola baku pertemuan guru-siswa di kelas dan waktu tertentu (Sartono, 2016).

Madrasah Aliyah Mu'allimin Mu'allimin Rembang pada masa pandemi COVID-19 juga melaksanakan pembelajaran secara daring. Beberapa platform yang digunakan dalam pembelajaran itu adalah whatapps grup, power point dan penjelasan guru menggunakan voicenote. Selain itu ada juga guru yang menggunakan video dengan persentasi sangat kecil. Rendahnya kemampuan guru dalam membuat media pembelajaran menjadikan pola pembelajaran monoton, sehingga membosankan siswa. Belum banyak guru memiliki kemampuan memanfaatkan teknologi informasi seperti Blog dan YouTube untuk menunjang kegiatan belajar mengajar.

Fasilitas internet dan komputer merupakan faktor utama untuk menerapkan pembelajaran berbasis e-learning. Selain itu, pengetahuan pengajar tentang Blog dan YouTube sebagai salah satu media pembelajaran berbasis E-Learning, masih kurang maksimal. Oleh karena itu dilakukan penyuluhan tentang Blog dan YouTube agar optimalisasi pembelajaran berbasis ELearning di Madrasah Mu'allimin Mu'allimat Rembang dapat tercapai.

Pemanfaatan Blog mempengaruhi proses pembelajaran. Media Blog mampu meningkatkan keaktifan siswa (Sartono, 2016). Web Blog merupakan alternatif penyampaian pengetahuan, informasi pada pembelajaran online serta sebagai solusi atas kurangnya pembelajaran konvensional di kelas (Nugroho, 2017). Blog sebagai media pembelajaran yang interaktif, mampu memberikan informasi dan mendukung model pembelajaran dengan teks, audio, video sehingga memudahkan proses pembelajaran (Wahyudi, 2014).

Blog sebagai media alternatif membuat pembelajaran lebih bervariasi (Andriayanto, 2018). Selain Blog, YouTube juga merupakan model pembelajaran daring (Kamhar dan Lestari, 2019). YouTube mampu meningkatkan minat dan motivasi belajar siswa (Mujianto, 2019). 
Pembelajaran menjadi efektif serta memudahkan siswa dalam mengerjakan soal (Pratiwi dan Hapsari, 2020). YouTube sebagai media pembelajaran alternatif mampu menaikkan kualitas pembelajaran guru di masa pandemi COVID-19 (Sari, 2020).

Permasalahan yang dihadapi adalah platform Blog dan YouTube tidak dimanfaatkan secara maksimal untuk pembelajaran terutama oleh guru-guru Madrasah Aliyah Mu'allimin Mu'allimat Rembang. Oleh karena itu, perlu optimalisasi pemanfaatan teknologi informasi media Blog dan YouTube untuk mendukung pembelajaran daring di madrasah itu.

Tujuan diselenggarakannya kegiatan ini adalah sebagai wujud pengabdian masyarakat dalam meningkatkan kualitas pembelajaran di Madrasah Mu'allimin Mu'allimat Rembang melalui upaya peningkatan kemampuan guru dalam pemanfaatan teknlogi informasi menggunakan platform Blog dan YouTube.

Harapan dari hasil program kegiatan ini adalah meningkatnya kemampuan guru Madrasah Mu'allimin Mu'allimat Rembang dalam membuat media pembelajaran yang lebih kreatif sehingga meningkatkan kualitas pembelajaran.

\section{METODOLOGI PELAKSANAAN}

Pelaksanaan kegiatan pengabdian kepada masyarakat ini dimulai dengan mengadakan kunjungan prasurvei ke Madrasah Aliyah Mu'allimin Mu'allimin di Jl. Pahlawan No. 43, Kabongan Kidul, Kecamatan Rembang, Kabupaten Rembang, 24 Oktober 2020 untuk pengurusan izin pelaksanaan kegiatan. Tim yang berkunjung terdiri dari dosen dan mahasiswa.

Setelah itu diselenggarakan sosialisasi mengenai manfaat media pembelajaran berbasis teknologi informasi pada 7 November 2020. Tim PKM melakukan sosialisasi mengenai manfaat media pembelajaran berbasis teknologi informasi. Tujuan diadakannya sosialisasi agar guru mengetahui manfaat digitalisasi media pembelajaran.

Kegiatan pengenalan dan pelatihan penggunaan platform Blog dilaksanakan 10 November 2020. Kegiatan tersebut dilakukan dengan tujuan agar guru mengetahui dan bisa menggunakan platform Blog. Tahapan kegiatan yang dilakukan meliputi: (1) penjelasan mengenai Blog sebagai sarana memublikasikan materi ajar dan materi tersebut bisa di download; (2) melakukan praktik agar guru bisa memanfaatkan Blog sebagai media pembelajaran.

Sementara itu, kegiatan pengenalan dan pelatihan penggunaan platform YouTube dilaksanakan 17 November 2020. Kegiatan tersebut dilakukan dengan tujuan agar guru 
mengetahui dan bisa menggunakan platform YouTube. Tahapan kegiatan yang dilakukan adalah: (1) penjelasan mengenai YouTube sebagai sarana memublikasikan materi berbentuk video, sehingga siswa dapat memutar ulang materi ajar kapan pun juga; (2) melakukan praktik atas penjelasan yang sudah dipaparkan agar guru bisa memanfaatkan YouTube sebagai media pembelajaran.

Pendampingan platform Blog dilakukan sebagai tindak lanjut dari program untuk memastikan tenaga pengajar mampu mengimplementasikan program yang telah dipaparkan sebelumnya. Pendampingan dilaksanakan 24 November 2020. Dari pendampingan diketahui beberapa guru mengalami kendala dalam menerapkan program dan beberapa guru lainnya mengalami kesulitan mengoperasikan sistem operasi Blog.

Pada 28 November 2020 dilakukan kembali pendampingan untuk platform YouTube karena ada kendala yang dihadapi guru, diantaranya kolom komentar nonaktif, sehingga video yang di-upload tidak bisa dikomentari orang lain.

\section{HASIL DAN PEMBAHASAN}

Kegiatan PKM dilakukan melalui tahapan sosialisasi, pelatihan dan pendampingan. Tahap sosialisasi ditujukan bagi seluruh guru Madrasah Aliyah Mu'allimin Mu'allimin yang berjumlah 25 orang. Peserta diberikan informasi mengenai pemanfaatan teknologi informasi sebagai media pembelajaran berbasis online. Dimulai dari latar belakang diselenggarakannya pembelajaran berbasis digital, konsep pembelajaran digital, analisis dan rancangan pengembangan pembelajaran sampai manajemen mutu pembelajaran berbasis digital.

Ditekankan bahwa pembelajaran berbasis digital tidak digunakan untuk mengganti model pembelajaran yang dilaksanakan secara konvensional, tetapi lebih diarahkan untuk meningkatkan mutu, kualitas dan layanan pendidikan jarak jauh. Di akhir penyampaian materi, dilakukan evaluasi melalui beberapa pertanyaan terkait materi yang telah disampaikan. Selain itu terdapat pula pemberian tugas untuk mempersiapkan bahan-bahan yang akan digunakan untuk pembuatan Blog dan channel YouTube.

Sebagai tindak lanjut dari sosialisasi, dilakukan pengenalan dan pelatihan Blog dan YouTube, diikuti 20 guru di Madrasah Aliyah Mu'allimin Mu'allimin. Pada kegiatan ini guru mendapatkan pengalaman, melakukan praktik langsung, membuat akun Blog dan akun YouTube.

Materi pelatihan dan praktik disampaikan mahasiswa dan dosen. Kegiatan pengenalan dan pelatihan Blog dan YouTube, dimulai dengan pengenalan platform Blog dan YouTube. Hampir 90 persen guru sudah mempunyai e-mail untuk account mendaftar Blog dan YouTube. 
Gambar 1. Persiapan Tim; Sosialisasi Blog dan YouTube; Pelatihan Penggunaan Blog dan YouTube, serta Pendampingan pelatihan mengoperasikan Blog dan YouTube
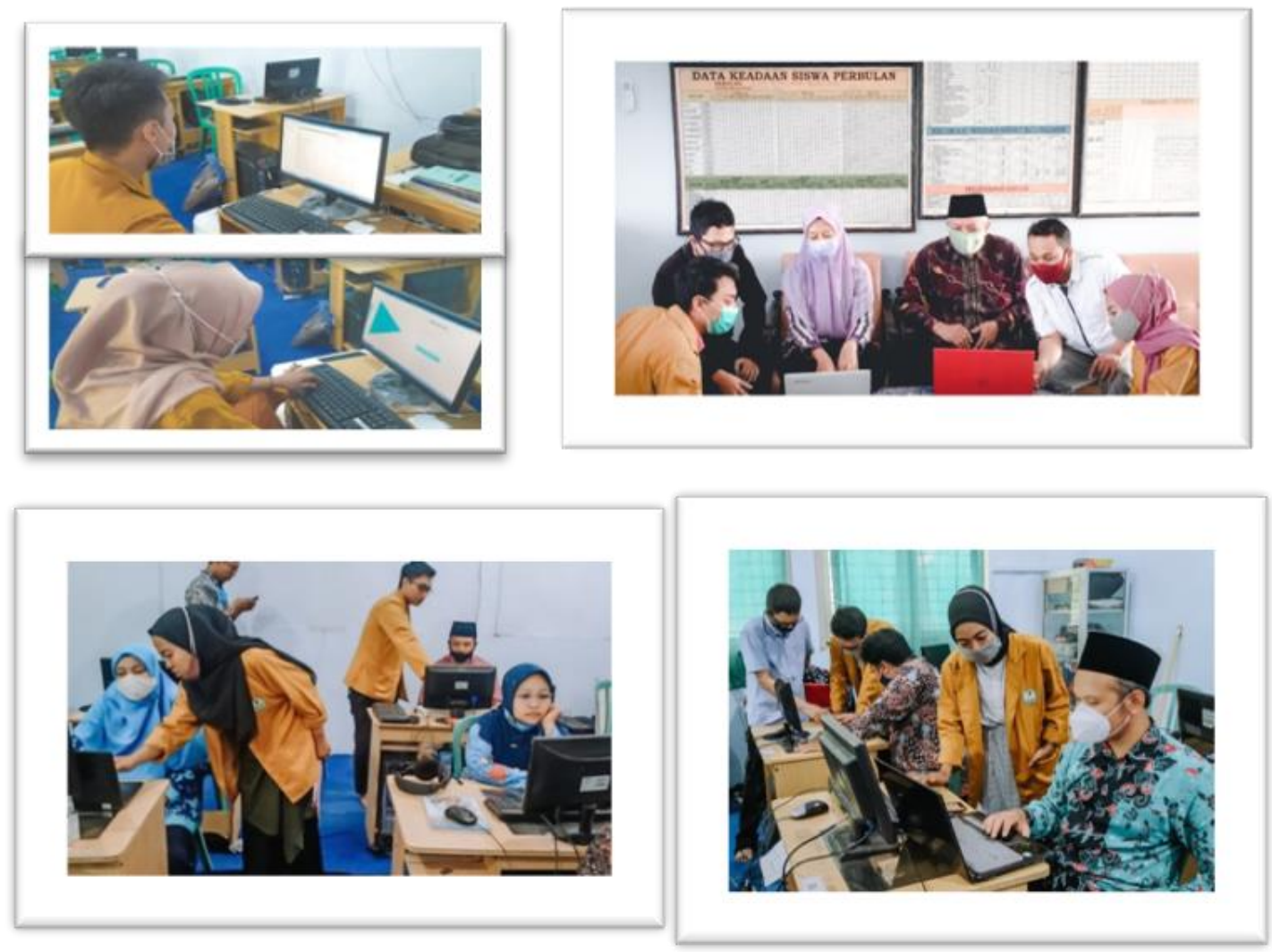

Tahapan pelatihan penggunaan Blog dan YouTube diawali dengan melakukan login menggunakan e-mail, dilanjutkan pengenalan konfigurasi-konfigurasi awal sampai dengan menyajikan konten pendidikan seperti posting artikel, menayangkan presentasi, membuat link download dan lain sebagainya.

Hasil dari pelaksanaan pelatihan adalah, guru bisa melakukan share materi dan membuat link download materi yang di-share di Blog. Guru juga kini memiliki akun channel YouTube sebagai media pembelajaran berbasis video digital sehingga memudahkan siswa belajar, dengan melihat video pembelajaran dari guru. Hal ini mengkombinasikan antara belajar dan hiburan, sehingga siswa tidak bosan belajar. Guru juga dapat me-upload video pembelajaran di channel YouTube, dan siswa dapat mengaksesnya menggunakan gadget kapan dan di mana saja.

Hasil evaluasi program PKM menyimpulkan terjadi peningkatan pemanfaatan teknologi dan informasi (IT), sehingga untuk poin pemanfaatan media pembelajaran dan model pembelajaran terjadi inovasi, dari sebelumnya menggunakan 50 persen media konvensional, sekarang telah memanfatkan media berbasis teknologi informasi. 


\section{SIMPULAN}

Kesimpulan yang dapat diambil pada kegiatan PKM ini adalah sebagai berikut: (1) peningkatan kemampuan guru dalam rangka pembuatan Blog dan channel YouTube sebagai media pembelajaran dapat dilakukan dengan cara pelatihan dan pendampingan program; (2) luaran produk program PKM ini adalah guru di Madrasah Aliyah Mu'allimin Mu'allimin telah mempunyai Blog dan channel YouTube sebagai media pembelajaran yang dapat diakses oleh siswa serta sebagai penunjang media pembelajaran.

Model pembelajaran berbasis teknologi informasi dengan memanfaatkan Blog dan YouTube sebagai media pembelajaran tidak diarahkan untuk menghi-langkan atau meminimalkan fungsi pembelajaran konvensional, namun lebih diarahkan sebagai suatu upaya untuk mengisi kekurangan yang ada pada metode pembelajaran konvensional.

\section{DAFTAR PUSTAKA}

Andriyanto \& Muslikh. (2018). Pelatihan Pembuatan Blog Sebagai Alternatif Media Pembelajaran. Jurnal Pengabdian Masyarakat IImu Keguruan dan Pendidkan, 2(1). https://doi.org/10.31326/jmp-ikp.v2i01

Elisvi, J., Archanita, R., Wanto, D., \& Warsah, I. (2020). Analisis Pemanfaatan Media Pembelajaran Online Di SMK IT Rabbi Radhiyya Masa Pandemi COVID-19. Al-Tarbawi Al-Haditsah: Jurnal Pendidikan Islam, 5(2), 16-42. http://dx.doi.org/10.24235/tarbawi.v5i2.6721

Herliandry L.D., Nurhasanah, Suban M. E., \& Kuswanto H., (2020). Pembelajaran Pada Masa Pandemi COVID-19. Jurnal Teknologi Pendidikan, 22(1). 65-70. https://doi.org/10.21009/jtp.v22i1.15286

Kamhar M.Y., \& Lestari, E. (2019). Pemanfaat Sosial Media YouTube Sebagai Media Pembelajaran Bahasa Indonesia Di Perguruan Tinggi. Inteligensi: Jurnal IImu Pendidikan, 1(2), 1-7. http://dx.doi.org/10.33366/ilg.v1i2.1356

Mujianto, H. (2019). Pemanfaatan YouTube Sebagai Media Ajar dalam Meningkatkan Minat dan Motivasi Belajar. Jurnal Komunikasi Universitas Garut: Hasil Pemikiran dan Penelitian, 5(1), 135-159. http://dx.doi.org/10.10358/jk.v5i1.588

Nugroho, A. A., Putra, R. W. Y., Putra, F. G., \& Syazali, M. (2017). Pengembangan Blog sebagai Media Pembelajaran Matematika. Al-Jabar: Jurnal Pendidikan Matematika, 8(2), $197-$ 203. https://doi.org/10.24042/ajpm.v8i2.2028 
Pratiwi, B., \& Hapsari, K. P. (2020). Kemampuan Berpikir Tingkat Tinggi dalam Pemanfaatan YouTube sebagai Media Pembelajaran Bahasa Indonesia. Jurnal Ilmiah Sekolah Dasar, 4(2), 282-289. http://dx.doi.org/10.23887/jisd.v4i2.24238

Sartono. (2016). Pemanfaatan Blog sebagai Media Pembelajaran Alternatif di Sekolah. Transformatika, 12(1), 107-120. http://dx.doi.org/10.31002/transformatika.v12i1.205

Sari, L. (2020). Upaya Menaikkan Kualitas Pendidikan dengan Pemanfaatan YouTube sebagai Media Ajar pada Masa Pandemi COVID-19. Jurnal Tawadhu, 4(1), 1074-1084.

Wahyudi, N. (2014). Pemanfaatan Blog Sebagai Media Pembelajaran Interaktif. Jurnal Studi Islam Pancawahana, 12(10), 85-94. 